\title{
SP-40,40, a Newly Identified Normal Human Serum Protein Found in the SC5b-9 Complex of Complement and in the Immune Deposits in Glomerulonephritis
}

\author{
Brendan F. Murphy," Louis Kirszbaum, ${ }^{\ddagger}$ Ian D. Walker, ${ }^{\ddagger}$ and Anthony J. F. d’Apice* \\ *Department of Nephrology, the Royal Melbourne Hospital and Department of Medicine, University of Melbourne, \\ and ${ }^{\ddagger}$ Research Centre for Cancer and Transplantation, University of Melbourne, Melbourne 3052, Australia
}

\begin{abstract}
We report herein the isolation and initial characterization of a novel protein, termed SP-40,40, which is present at moderate levels $(35-105 \mu \mathrm{g} / \mathrm{ml})$ in normal human serum. SP-40,40 is deposited in the renal glomeruli of patients with glomerulonephritis but is not found in normal glomeruli. The protein is a heterodimeric structure of relative molecular mass $80 \mathrm{kD}$, both chains of which are of a similar size $(40 \mathrm{kD})$. The amino-terminal sequences of both chains are unrelated to one another and possess no significant homology to any known protein sequence.

The tissue distribution of SP-40,40 closely resembles that of the terminal complement components and its physicochemical properties are similar to, but distinct from, those of the $\mathbf{S}$ protein of complement. We have identified SP-40,40 in the SC5b-9 complex of complement and have demonstrated incorporation of labeled SP-40,40 into this complex. These data suggest that SP-40,40 is an additional component of SC5b-9.
\end{abstract}

\section{Introduction}

We have recently demonstrated that monoclonal antibody (MAb) technology can be used to identify the individual components of the immune deposits in human glomerulonephritis (1). Glomerular immune deposits generally contain host antibody and complement components (2) including the assembled membrane attack complex (3). The identities of putative antigen moieties of the immune deposits (2) and of other potential mediators of tissue damage are generally unknown and it was to enable their identification that this approach was used (1).

During the course of these studies we have produced a number of MAbs reactive with glomerular immune deposits. Two of these (E5 and G7) are directed against a previously undescribed normal human serum protein. This article describes the production of these MAbs and the purification from normal serum and biochemical characterization of the protein, which we have provisionally named SP-40,40 (serum protein $40 \mathrm{kD}, 40 \mathrm{kD}$ ) on the basis of its biochemical structure.

A preliminary report of part of this work has appeared in abstract form (1988. Kidney Int. 33:137).

Address correspondence and reprint requests to Dr. Murphy at his current address: Renal Unit, St. Vincent's Hospital, Fitzroy, Melbourne 3065, Australia.

Received for publication 13 May 1987 and in revised form 22 October 1987.

J. Clin. Invest.

(c) The American Society for Clinical Investigation, Inc.

0021-9738/88/06/1858/07 \$2.00

Volume 81, June 1988, 1858-1864
The identification of SP-40,40 as an additional component of the SC5b-9 complex of complement is also described.

The attack complex of complement (comprising C5b, C6, $\mathrm{C7}, \mathrm{C} 8$, and C9) may be generated in two ways. When complement is activated on a phospholipid membrane, the nascent attack complex becomes amphiphilic upon the acquisition of C7 and inserts into the membrane (4-7). C8 and multiple molecules of $\mathrm{C} 9$ then bind to the complex to form the membrane complement lesion (8). This may be referred to as MC5b-9 (9) or C5b-9(m) (7). ${ }^{1}$ If the attack complex is assembled in the fluid phase by the activation of normal human serum (NHS), an additional serum protein, the $S$ protein, binds to the amphiphilic C5b-7 complex rendering it once more hydrophilic $(7,10)$. C8 and C9 combine with this complex but the polymerization of $\mathrm{C} 9$ is inhibited by the $\mathrm{S}$ protein (11). The resulting hydrophilic complex is referred to as SC5b-9 (10), denoting the presence of the S protein.

Recent studies have identified $S$ protein in the immune deposits in glomerulonephritis with a distribution similar to that of the terminal complement components $(12,13)$. This suggests that at least part of the attack complex in the glomerulus must be in the SC5b-9 form; either derived from circulating SC 5b-9 or from locally assembled C5b-9 which has bound $S$ protein.

\section{Methods \\ Production of monoclonal antibodies}

A postmortem kidney was obtained from a patient with membranous glomerulonephritis and glomerular basement membrane (GBM) prepared by ultrasonication (14). BALB/c mice were immunized twice subcutaneously with GBM (equivalent to 3,000 glomeruli per injection) in Freund's adjuvant and killed $3 \mathrm{~d}$ after an intraperitoneal injection of a similar quantity of GBM in 0.1 M PBS. Mouse spleen cells were fused with SP 2/0.Ag8 myeloma cells according to the method of Oi and Herzenberg (15). Culture supernatants were initially screened immunohistologically (16) on simultaneous sections of the kidney used for immunization and normal human kidney. Cultures producing supernatants reactive with diseased glomeruli, but not with normal glomeruli, were cloned (15) for further study.

\section{Characterization of cloned monoclonal antibodies}

ELISA studies. Culture supernatants were screened by ELISA $(1,17)$ for reactivity with NHS, purified human IgG, IgA (Sigma Chemical Co., St. Louis, MO), and IgM (Silenus Laboratories, Melbourne, Australia), purified C5b-9(m) and SC5b-9 complexes (9, and see below), and purified human complement components $(\mathrm{C} 3, \mathrm{C} 5, \mathrm{C} 6, \mathrm{C} 7, \mathrm{C8}$, C9) (Calbiochem-Behring Corp., La Jolla, CA).

EAC1423 binding assay. Sheep erythrocytes coated with antisheep $E$ antibody and reacted with human complement components 1 ,

1. Abbreviations used in this paper: $\mathrm{C} 5 \mathrm{~b}-9(\mathrm{~m})$ or MC5b-9, membraneassembled attack complex of complement; GBM, glomerular basement membrane; IEF, isoelectric focusing; NHS, normal human serum; PEG, polyethylene glycol; SC5b-9, fluid-phase assembled attack complex of complement containing the $S$ protein. 
4, 2, and 3 (EAC1423) were prepared as described (18). The binding of the MAbs to washed EAC1423 target cells was measured in a radioimmunoassay as described (19). A MAb reactive with human C3, produced in our laboratory, was used as a positive control.

\section{$C 5 b-9(m)$ and $S C 5 b-9$ purification}

C5b-9(m) complexes were purified by the method of Ware et al. (9). Antibody-coated sheep erythrocytes were lysed with NHS and the C5b-9(m) complexes extracted with Zwittergent 3-12 (CalbiochemBehring Corp.) and further purified by gel filtration on Biogel A-15M (Bio-Rad Laboratories, Richmond, CA).

SC5b-9 complexes were purified by two separate methods:

Affinity chromatography. A modification of the method of Ware et al. (9) was used. Inulin-activated NHS was passed through an affinity column containing an anti-C 9 MAb produced in our laboratory. After extensive washing with PBS containing $10 \mathrm{mM}$ EDTA, the column was eluted with $2 \mathrm{M}$ guanidine $\mathrm{HCl}$ (Sigma Chemical Co.). After dialysis of the eluate against PBS, the SC5b-9 was further purified by gel filtration using a Superose 6 (Pharmacia Fine Chemicals, Uppsala, Sweden) column and a Pharmacia FPLC system. The high-molecularmass fractions were subjected to SDS-PAGE and the identity of the components of SDS-PAGE pure SC5b-9 was confirmed by Western blotting (see below).

$D E A E$-Sephacel chromatography. This method was adapted from that of Bhakdi and Roth (20). Inulin-activated NHS was fractionated with polyethylene glycol (PEG) $\mathbf{4 0 0 0}$ (E. Merck, Darmstadt, Federal Republic Germany) and the 5-10\% PEG precipitate was then applied to a DEAE-Sephacel column (Pharmacia Fine Chemicals). After washing, the column was eluted with $100-500 \mathrm{mM} \mathrm{NaCl}$ gradient. Fractions were tested by ELISA for the presence of C5, C6, C7, C8, and $\mathrm{C} 9$ and those fractions containing all five components were pooled and further purified by gel filtration using a Superose 6 column as described under Affinity chromatography above. Fig. 1 shows SDS-PAGE gels of both preparations of SC5b-9 with no contaminating proteins present.

\section{Affinity purification of SP-40,40}

The G7 MAb was coupled to Affigel 10 (Bio-Rad Laboratories) according to the manufacturer's instructions. $20 \mathrm{ml}$ of fresh NHS was passed over $3 \mathrm{ml}$ of the affinity gel, and the column was washed with $200 \mathrm{ml}$ of PBS and eluted with $30 \mathrm{ml}$ of $0.2 \mathrm{M}$ glycine, $0.5 \mathrm{M} \mathrm{NaCl}$ (pH 2.8), $\mathrm{HCl}$. Repeated elutions were dialyzed against PBS, pooled, concentrated in an Amicon Corp. (Danvers, MA) ultrafiltration cell (YM 10 membrane), and subjected to SDS-PAGE.

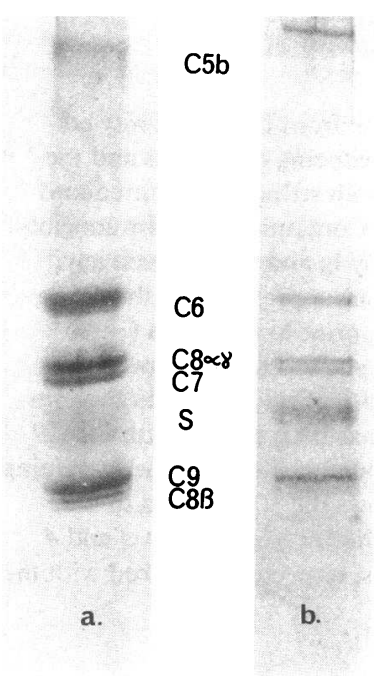

Figure 1. SDS-PAGE gels of SC5b-9 complexes. (a) DEAE-Sephacel-purified SC5b-9 $(25 \mu \mathrm{g})$ and $(b)$ affinity-purified SC $5 \mathrm{~b}-9$ (5 $\mu \mathrm{g})$. A $7.5 \%$ acrylamide separating gel was used and protein was detected with a silver stain (Bio-Rad Laboratories).

\section{$S D S-P A G E$}

SDS-PAGE was performed according to the method of Laemmli (21). Protein was detected using Coomassie Blue R250 or with a silver stain (Bio-Rad Laboratories). Additional gels were stained with periodic acid-Schiff's reagent (22) to detect carbohydrate.

\section{Western blotting}

Approximately $10 \mu \mathrm{g}$ of protein was electrophoresed in wide lanes on SDS-PAGE gels and transferred to nitrocellulose paper (Bio-Rad Laboratories) as described (23). Separate gels were used for reduced and nonreduced samples. The nitrocellulose was cut into strips and probed with the $G 7$ or E5 MAbs and ${ }^{125}$ I-labeled $F(a b)_{2}$ goat anti-mouse immunoglobulins (Pel Freeze Biologicals, Rogers, AR) and subjected to autoradiography.

When Western blotting was performed with purified C $5 \mathrm{~b}-9(\mathrm{~m})$ and SC5b-9 complexes, immunoprobing was also performed as above using a MAb against $S$ protein (Cytotech, San Diego, CA). Further strips were probed with polyclonal antisera against human complement components C5, C6, C7, C8, C9 (Calbiochem-Behring Corp.) followed by ${ }^{125}$ I-labeled antisera (IgG fractions) to goat (Kirkegaard and Perry Laboratories, Gaithersburg, MD) or rabbit (Dako, Denmark) immunoglobulins.

\section{Reverse-phase high performance liquid chromatography}

Approximately $100 \mu \mathrm{g}$ of affinity-purified SP-40,40 was dissolved in $200 \mu \mathrm{l}$ of $6 \mathrm{M}$ guanidinium hydrochloride, $0.1 \mathrm{M}$ Tris, $\mathrm{pH} 8.0(\mathrm{HCl})$. Half of the sample was treated with dithiothreitol $(50 \mathrm{mM})$ for $1 \mathrm{~h}$ and then both samples were carboxamidomethylated using $110 \mathrm{mM}$ iodoacetamide $(15 \mathrm{~min})$. The samples were then subjected to reverse-phase HPLC using a complete Pharmacia FPLC system and a Pro RPC (C8) column. Samples were eluted at a flow rate of $1 \mathrm{ml} / \mathrm{min}$ with a linear gradient of acetonitrile $(0-90 \% \mathrm{wt} / \mathrm{vol})$ buffered with $20 \mathrm{mM}$ formic acid, $\mathrm{pH} 4.0\left(\mathrm{NH}_{3}\right)$. The gradient was delivered over $50 \mathrm{~min}$ and peaks were detected by absorbance at $280 \mathrm{~nm}$.

\section{Amino-terminal sequence analysis}

Automatic sequence analysis was performed using a model $470 \mathrm{~A}$ sequencer (Applied Biosystems, Inc., Foster City, CA) and an HPLC (Waters Associates, Millipore Corp., Milford, MA) for PTH amino acid detection (24).

A computer-assisted homology search was conducted to determine if either the $\alpha$ - or the $\beta$-chain sequences of SP-40,40 bore homology to any other sequence within the PIR, Doolittle, GENBANK, and Ooi data bases. Both mutation data matrix and unitary matrix scoring systems were used.

\section{Agarose gel electrophoresis}

Agarose gel electrophoresis of concentrated unreduced SP-40,40 was performed using a Paragon protein electrophoresis unit according to the manufacturer's instructions (Beckman Instruments, Inc., Palo Alto, CA). The SP-40,40 was dissolved in water at a concentration of $\sim 5 \mathrm{mg} / \mathrm{ml}$ and $5 \mu \mathrm{l}$ was applied via a template. NHS was applied in an adjacent lane. Electrophoresis was for $30 \mathrm{~min}$ at $100 \mathrm{~V}$ in barbitalcontaining buffer, $\mathrm{pH} 8.6$, and the gel was stained with Coomassie Blue R250.

\section{Isoelectric focusing}

Isoelectric focusing (IEF) of purified SP-40,40 was performed using a Multiphor I flatbed electrophoresis unit (LKB Produkter, Bromma, Sweden) and polyacrylamide gels (LKB PAG plates) with pH 3.5-9.5 ampholines. $20 \mathrm{ml}$ of SP-40,40 $(1.5 \mathrm{mg} / \mathrm{ml}$ in water) was applied 1.5 $\mathrm{cm}$ from the cathode and a sample of IEF standards (Broad pI Calibration Kit, Pharmacia Fine Chemicals) was applied at one-third of the distance between the anode and the cathode. IEF was carried out for 90 min at a constant power of $30 \mathrm{~W}$. The gel was stained with Coomassie Blue R250 and the pI of the protein standards was marked according to data supplied by the manufacturer. 
Determination of the normal serum concentration of $S P-40,40$

The concentration of SP-40,40 in normal serum was estimated by a double-antibody sandwich ELISA assay (25) using the two anti-SP40,40 MAbs. Microtiter plates were precoated with the E5 MAb and then incubated sequentially with serum samples (diluted 1:10 in PBS) and the G7 monoclonal antibody which had been conjugated to alkaline phosphatase (Sigma Chemical Co.) as described (25). Color was developed with $p$-nitrophenyl phosphate (Sigma Chemical Co.) and plates were read at $405 \mathrm{~nm}$. Chromatographically purified SP-40,40 of known concentration (estimated by absorbance at $205 \mathrm{~nm}$ [26]) was used as a standard.

\section{Native molecular mass}

The native molecular mass of immunoreactive SP-40,40 was estimated by gel filtration of normal serum on calibrated Sephacryl S-200 and Superose 6 columns. The concentration of SP-40,40 in the fractions was estimated using the double-antibody ELISA.

\section{ELISA with purified SP-40,40}

Further ELISA studies were performed using, as the antigen, affinityand FPLC-purified SP-40,40. Plates were coated with SP-40,40 (50 $\mu \mathrm{g} / \mathrm{ml}$ ) and duplicate wells were incubated with either the $\mathrm{G} 7$ or the E5 MAbs or a MAb reactive with the $S$ protein of complement (Cytotech) followed by alkaline phosphatase-conjugated antibody to mouse immunoglobulins (Kirkegaard and Perry Laboratories). Additional wells were incubated with anti-S-protein antiserum (Calbiochem-Behring Corp.) followed by alkaline phosphatase-conjugated antibody to rabbit immunoglobulins (Kirkegaard and Perry Laboratories). Color was developed with p-nitrophenyl phosphate.

Incorporation of labeled SP-40,40 into the SC5b-9 complex $150 \mu \mathrm{g}$ of affinity- and FPLC-purified SP-40,40 was labeled with $1 \mathrm{mCi}$ ${ }^{125}$ I (Amersham Int., Amersham, Bucks, UK) using the lactoperoxidase technique (27). Unbound iodine was separated by gel filtration on a PD10 Sephadex column (Pharmacia Fine Chemicals) and the labeled SP-40,40 was added to $60 \mathrm{ml}$ of fresh NHS. The serum was inulin activated and the SC $5 \mathrm{~b}-9$ complexes purified by DEAE-Sephacel chromatography and gel filtration as described above. Reduced and nonreduced samples of the purified SC5b-9 complexes were subjected to SDS-PAGE and the dried gels autoradiographed to detect labeled SP-40,40. The activity of the labeled SP-40,40 and of the purified SC5b-9 complexes was also estimated using a model A5412 gamma counter (Hewlett-Packard Co., Palo Alto, CA) to determine the proportion of the labeled SP-40,40 incorporated in the complexes.

\section{Immunohistologic studies}

Five normal kidneys, samples of normal lung, liver, and spleen, and renal biopsies of 15 patients with various forms of glomerulonephritis (GN) (membranous GN, three patients; type 1 mesangiocapillary GN, three patients, IgA nephropathy, two patients, mesangial proliferative GN, three patients; lupus nephritis, two patients; focal glomerulosclerosis, two patients) were examined using a four-layer immunoperoxidase technique (28). Tissues were fixed in paraformaldehyde-lysineperiodate (28) and 3- $\mu \mathrm{m}$ frozen sections were cut and initially incubated with either culture supernatant of anti SP-40,40 MAb (E5 or G7) or MAbs against $\mathrm{C} 6$ or $\mathrm{C} 9$ (produced in our laboratory) or $\mathrm{S}$ protein (Cytotech). Sections were then sequentially illcubated with rabbit anti-mouse immunoglobulins (Z259, DAKO), excess swine anti-rabbit immunoglobulins (DAKO Z196), and complexes of horseradish peroxidase and rabbit anti-horseradish peroxidase (DAKO Z113). The color was developed with diaminobenzidine (Sigma Chemical Co.) and sections were counterstained with hematoxylin. Frozen sections of fresh material from all of the kidneys studied were also processed for standard immunofluorescence (29) using fluorescein-conjugated anti- sera to human immunoglobulins $\mathrm{G}, \mathrm{A}$, and $\mathrm{M}$ and complement components $\mathrm{C} 3$ and $\mathrm{Clq}$ (Wellcome, Beckenham, UK).

\section{Results}

Characterization of monoclonal antibodies. 12 MAbs were found to be reactive with glomeruli in sections of the immunizing kidney but not with normal glomeruli. 10 of these antibodies exhibited reactivity with NHS by ELISA and, of these, 8 were subsequently demonstrated to be reactive with known complement components. Their characterization is described in detail in another publication (1).

Two monoclonal antibodies (G7 and E5) reacted strongly with NHS by ELISA, but failed to react by ELISA with purified C5b-9(m) complexes, purified individual complement components $(\mathrm{C} 3, \mathrm{C} 5, \mathrm{C} 6, \mathrm{C} 7, \mathrm{C} 8$, and $\mathrm{C} 9)$ or with purified human immunoglobulins $G, A$, and $M$. They also failed to demonstrate binding to EAC 1423 cells by radioimmunoassay.

Both the G7 and E5 MAbs, however, demonstrated reactivity by ELISA with both preparations (affinity purified and DEAE-Sephacel purified) of SC5b-9 complexes.

Purification of SP-40,40. The concentrated eluate from the G7 affinity column column was subjected to SDS-PAGE. Electrophoresis without reduction showed a single major protein species with a molecular mass of $80 \mathrm{kD}$ (Fig. 2, left).
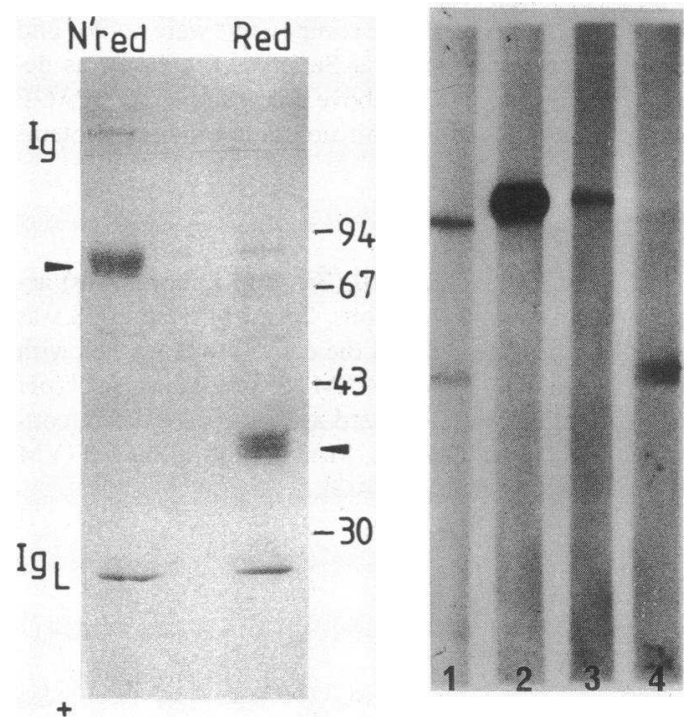

Figure 2. (Left) SDS-PAGE gels of eluate from the G7 affinity column. The left lane was run under nonreducing conditions and the right lane under reducing conditions. Both reduced and unreduced samples contained $\sim 40 \mu \mathrm{g}$ of protein. Contaminating immunoglobulin and free light chain are indicated by Ig and IgL, respectively, and the positions of molecular mass marker proteins are shown on the right in kilodaltons $(\mathrm{kD})$. SP-40,40, prior to reduction $(\sim 80$ $\mathrm{kD})$, and after reduction $(\sim 40 \mathrm{kD})$, is shown by the arrowheads. (Right) Autoradiograph of a Western blot of gels similar to those in left panel. In lane 1 a reduced sample has been probed with the G7 $\mathrm{MAb}$ and the $40-\mathrm{kD}$ band is demonstrated as well as some remaining unreduced $80-\mathrm{kD}$ material. Lane 2 shows the $80-\mathrm{kD}$ band in a nonreduced sample demonstrated by the G7 MAb. Lanes 3 and 4 show nonreduced and reduced samples, respectively, probed with the E5 MAb. 


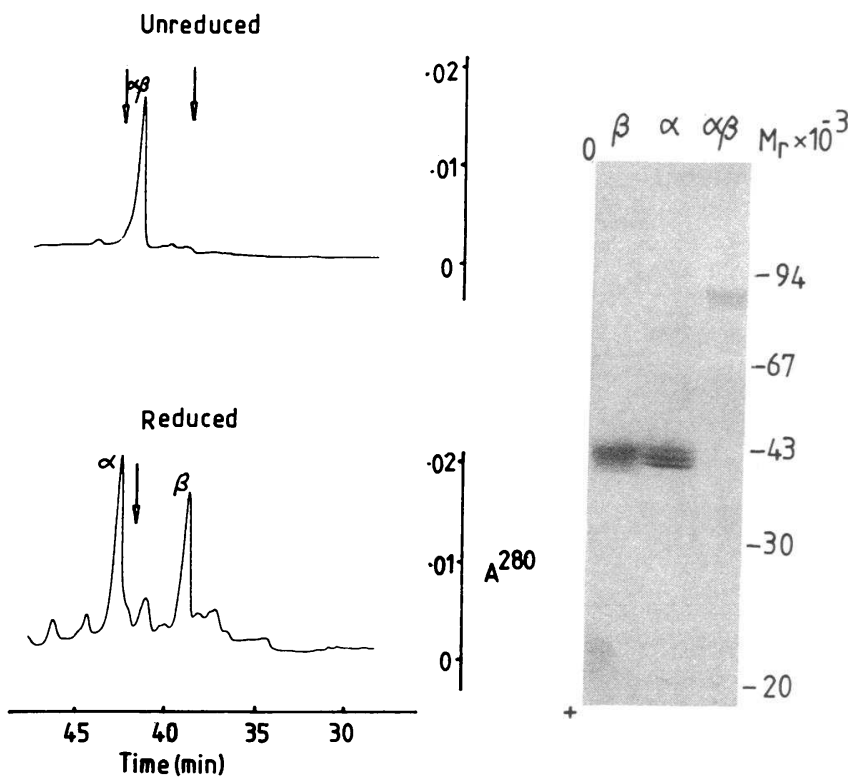

Figure 3. (Left) Reverse-phase HPLC of affinity-purified SP-40,40. The upper tracing is of nonreduced material and the lower tracing is of a reduced sample. Fractions corresponding to the peaks labeled $\alpha$, $\beta$, and $\alpha \beta$ were subjected to SDS-PAGE. (Right) SDS-PAGE of the $\alpha, \beta$, and $\alpha \beta$ zones. A $10 \%$ acrylamide separating gel was used and protein was detected with Coomassie Blue. Gel loadings were $20 \mu \mathrm{g}$ of each of the $\alpha$ and $\beta$ subunits and $10 \mu \mathrm{g}$ of the $\alpha \beta$ heterodimer.

Reduction of the material before electrophoresis resulted in the appearance of a heterodisperse polypeptide band of molecular mass $40 \mathrm{kD}$ (Fig. 2, left). Both the 80 - and $40-\mathrm{kD}$ bands were shown to be reactive with the G7 and E5 MAbs by Western blotting (Fig. 2, right). The G7 MAb appears to have a higher affinity for nonreduced SP-40,40 whereas the E5 MAb demonstrates greater reactivity with reduced SP-40,40.

Reverse-phase HPLC on a reduced and carboxamidomethylated sample is shown in Fig. 3 (left). Two constituent polypeptide chains were separated and these were arbitrarily designated $\alpha$ and $\beta$. SDS-PAGE analysis of purified native protein and the separated $\alpha$ - and $\beta$-chains is shown in Fig. 3 (right). Both the $\alpha$-and $\beta$-chains have a similar molecular mass $(40 \mathrm{kD})$. The electrophoretic microheterogeneity apparent in both unreduced SP-40,40 and in the constituent polypeptide chains probably represents differential glycosylation. Periodic acid-Schiff staining of similar gels confirmed the presence of carbohydrate moieties in both the native and reduced forms.

Amino-terminal sequence analysis. The separate identities of the $\alpha$ - and $\beta$-chains were established by sequence analysis. The amino-terminal sequences of both chains are presented in Fig. 4. No significant homology is apparent between the two sequences. The computer-assisted homology search revealed no statistically significant homology of either the $\alpha$-or the $\beta$-chain sequences of SP-40,40 to any other sequence within the data bases. Thus, both chains of SP-40,40 appear to be unique.

Electrophoretic mobility of SP-40,40. On agarose gel electrophoresis purified SP-40,40 migrated as an $\alpha$-globulin in the inter- $\alpha$ region (Fig. 5, left). IEF (Fig. 5, right) demonstrated several bands in the region pI 4.5-5.2. IEF of the separated $\alpha$ -

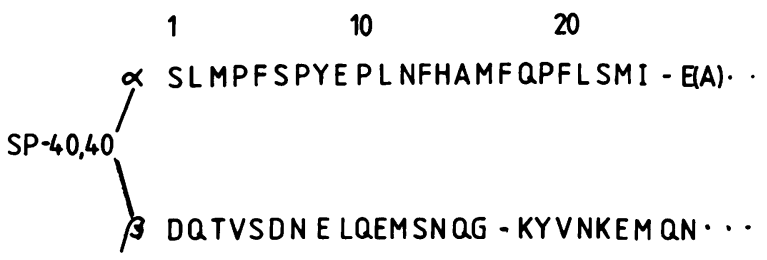

Figure 4. Amino-terminal sequences of the $\alpha$ - and $\beta$-chains of $\mathrm{SP}-40,40$. Blanks indicate that no residue assignment at these positions was possible.

and $\beta$-chains revealed overlapping but nonidentical patterns within this pI range.

Concentration of SP-40,40 in normal serum. The concentration of SP-40,40 was determined by ELISA in sera from 20 healthy volunteers ( 10 male, 10 female). Serum concentration ranged from 35 to $105 \mu \mathrm{g} / \mathrm{ml}$ with no significant sex difference. Median serum concentration was $62 \mu \mathrm{g} / \mathrm{ml}$. Levels in heparinized plasma samples were similar: $40-110 \mu \mathrm{g} / \mathrm{ml}$, median 72 $\mu \mathrm{g} / \mathrm{ml}$.

Native molecular mass. Repeated gel filtration experiments reproducibly yielded three peaks of immunoreactivity at $\sim 68$ $\mathrm{kD}, 160 \mathrm{kD}$, and a small peak corresponding to the void volume. The $68-\mathrm{kD}$ peak contained $\sim 60 \%$ of the immunoreactive protein and presumably represents the native heterodimer. The difference between this molecular mass estimation and that obtained by SDS-PAGE is probably due to the glycosylation of SP-40,40. Glycosylated proteins are known migrate more slowly in SDS-PAGE gels (30). The $160-\mathrm{kD}$ material may represent a dimeric form of SP-40,40 or SP-40,40 complexed to another serum protein.

SDS-PAGE and Western blotting of purified $C 5 b-9(m)$ and $S C 5 b-9$ complexes. $\mathrm{C} 5 \mathrm{~b}-9(\mathrm{~m})$ complexes were shown to be free of contaminating proteins by SDS-PAGE. After Western blotting C6, C7, C8, and C9 were detected in purified C5b-9(m) complexes (data not shown). The anti-C5 antiserum, which

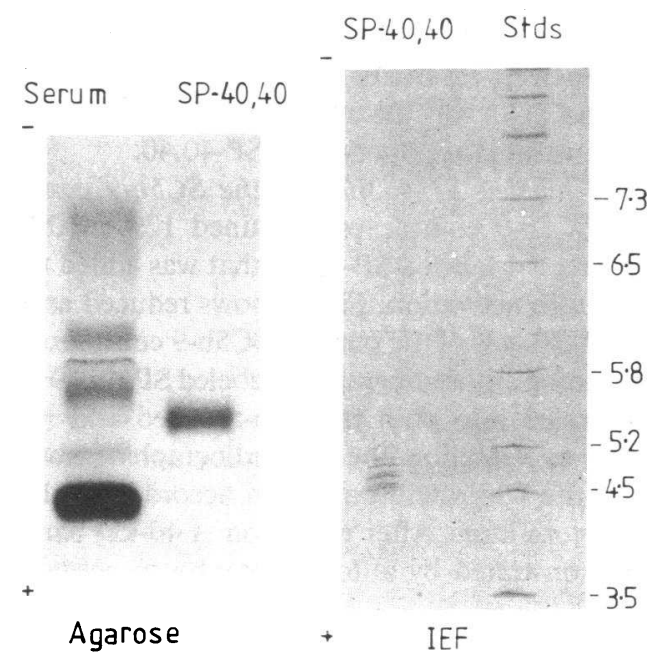

Figure 5. (Left) Agarose gel electrophoresis of concentrated unreduced SP-40,40 compared to a sample of NHS run simultaneously. (Right) IEF of purified SP-40,40. The isoelectric points of the protein standards are shown on the right. 


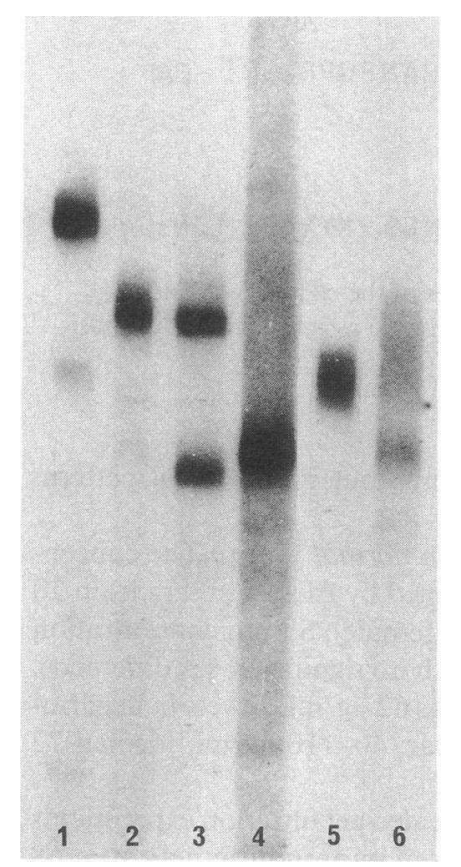

Figure 6. Autoradiograph of a Western blot of purified SC5b-9. The SDS-PAGE step was run under nonreducing conditions. Lane 1 is probed with antiserum against $\mathrm{C6}$.

Lane 2 is probed with antiserum against C7. Lane 3 is probed with antiserum against C8. Both C8 $\alpha \gamma$ (upper band) and $C 8 \beta$ (lower band) are demonstrated. Lane 4 is probed with antiserum against C9. Lane 5 is probed with MAb G7 (anti-SP-40,40); note 80-kD band comigrating with $S$ protein. Lane 6 is probed with the MAb against $S$ protein. There is a diffuse band of reactivity in the $80-90-\mathrm{kD}$ region as previously described (33). The characteristic 65-kD band of degraded $S$ protein (11) is also detected by the MAb.

reacted with the C5b-9(m) complexes by ELISA, failed to demonstrate $\mathrm{C} 5 \mathrm{~b}$ after immunoblotting.

When Western blotting was performed with the two preparations of SC5b-9 complexes, C6, C7, C8, C9 were detected. The $\mathrm{C} 5$ antiserum again failed to react. $\mathrm{S}$ protein was also demonstrated in the complexes and, in addition, immunoprobing with the G7 MAb revealed SP-40,40 as an additional component of both preparations of SC5b-9. Fig. 6 shows the autoradiograph of a Western blot of DEAE-sephacel purified SP-40,40. A similar appearance was seen when Western blotting was petformed with the same amount of affinity-purified SC5b-9, although the intensity of both the $S$ protein and SP-40,40 bands relative to the other components was somewhat less, suggesting that these may have been partially dissociated from SC $5 \mathrm{~b}-9$ during elution from the affinity column.

ELISA studies with purified SP-40,40. The G7 and E5 MAbs demonstrated strong reactivity by ELISA with purified SP-40,40. Neither the MAb nor the antiserum against S-protein, however, demonstrated reactivity with SP-40,40.

Incorporation of labeled SP-40,40 into the SC5b-9 complex. The purified SC5b-9 complexes contained $12 \%$ of the original activity of the ${ }^{125}$ I-labeled SP-40,40 that was added to the NHS prior to inulin activation. Fig. 7 shows reduced and nonreduced SDS-PAGE gels of the purified SC5b-9 complexes with their corresponding autoradiographs. Labeled SP-40,40 is seen to be incorporated into both the non-reduced and reduced SC5b-9. Prior to reduction, the autoradiograph demonstrates SP-40,40 in the "S-protein band," in accord with the findings on the Western blots. After reduction, a 40-kD band appears and is demonstrated by autoradiography to contain SP-40,40.

Immunohistologic distribution of $S P-40,40$. Immunoperoxidase studies with the G7 and E5 monoclonal antibodies revealed that, in normal kidney, there is reactivity with the intima of arteries but not with glomeruli. In glomerulonephritic kidneys, SP-40,40 is also deposited in the glomeruli in a

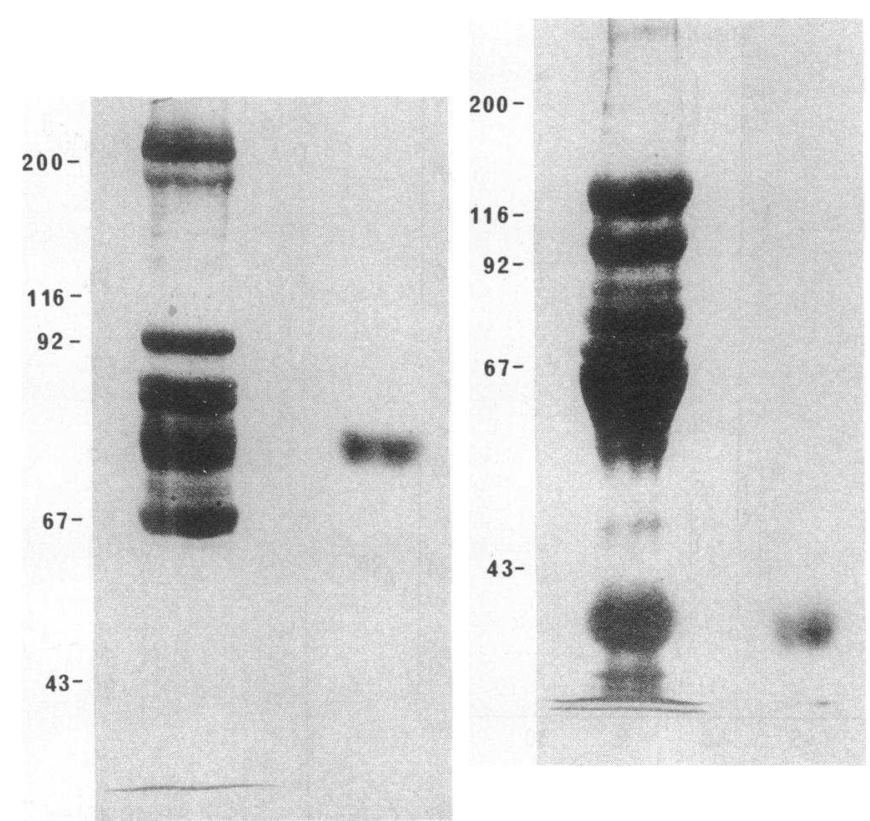

Figure 7. Coomassie Blue-stained SDS-PAGÉ gels and corresponding autoradiographs of SC5b-9 purified from NHS previously inulin-activated in the presence of ${ }^{125}$ I-labeled SP-40,40. $50 \mu \mathrm{g}$ of protein was lodded onto gels containing $7.5 \%$ acrylamide separating gels. The position of the molecular mass standards is shown on the left of each gel in kilodaltons (kD). (Left) Nonreduced SC5b-9; autoradiograph demonstrates the SP-40,40 comigrating with S protein. (Right) SC5b-9 after reduction. Note the appearance of a 40-kD band which, in the autoradiograph, contains SP-40,40.

pattern closely resembling the deposition of the immune deposits as detected by anti-immunoglobulin and anti-complement antibodies (Fig. 8). In addition, in chronically damaged kidnêys, SP-40,40 is present in a patchy distribution in Bowman's capsule, around tubules, and in areas of scarring. This latter pattern is identical to that observed for terminal complement components and $S$ protein by us and by other investigators $(3,12,13)$. SP-40,40 is also detectable in the intima of normal arteries throughout the body. Hepatic deposition is also confined to vessels.

\section{Discussion}

$\mathrm{SP}-40,40$ is a serum $\alpha$-glycoprotein of molecular mass $80 \mathrm{kD}$ comprising two distinct polypeptide chains, each of molecular mass $40 \mathrm{kD}$. It is present in NHS, but a detailed search through the literature on serum protein $(31,32)$ disclosed no previously described protein with the same physicochemical characteristics. Sequence analysis confirms that SP-40,40 is not a protein of known amino acid sequence, nor does it bear significant homology to any human or animal protein for which sequence data are available.

Immunohistologically, the distribution of SP-40,40 is strikingly similar to that of the terminal complement components and it does bear some resemblance to a known protein of the complement system, the S protein. Like SP-40,40, the S protein is an $\alpha$-globulin with an approximate molecular mass of $80 \mathrm{kD}$ (11). Neither SP-40,40 nor S protein is present in 


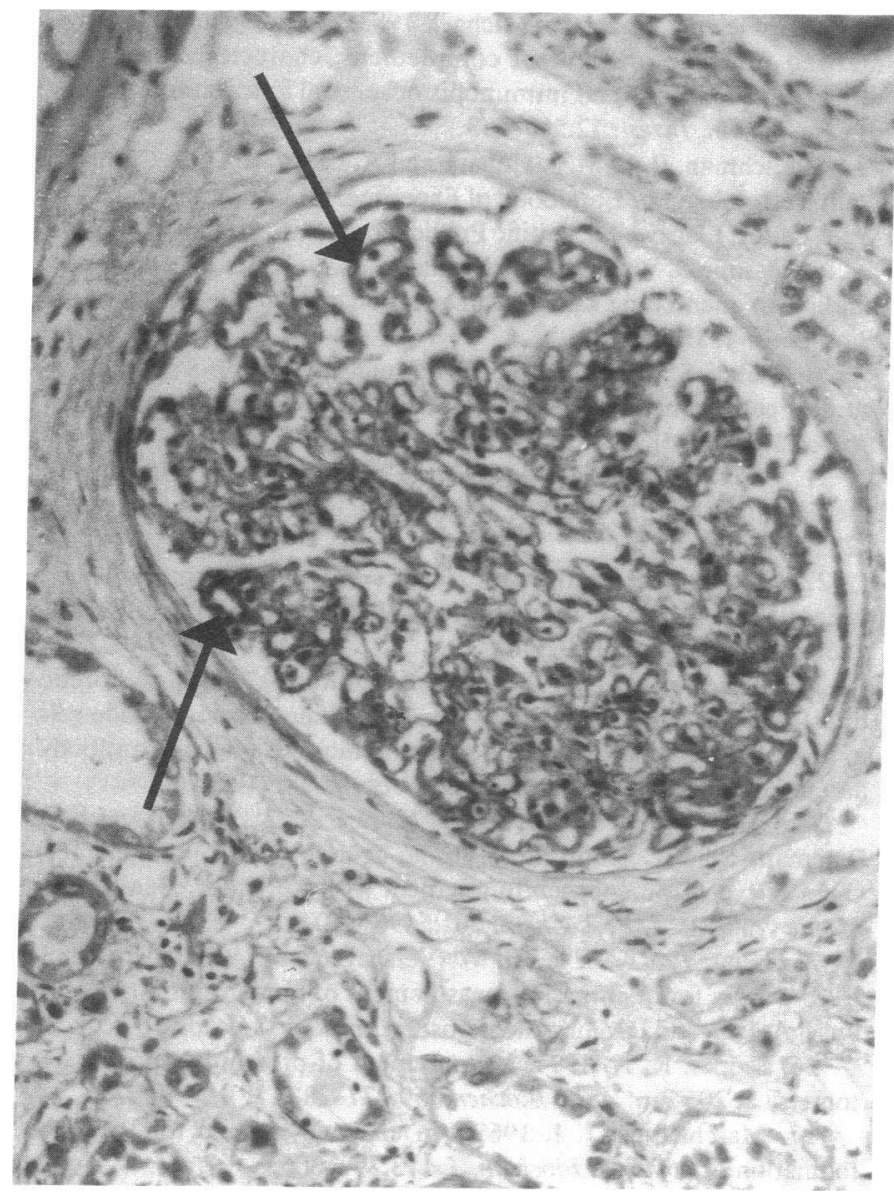

Figure 8. Photomicrographs $(\times 373)$ of sections of the kidney with membranous glomerulonephritis, against which the G7 and E5 MAbs were raised (left) and normal human kidney (right). Sections were labeled with the G7 (anti-SP-40,40) MAb by immunoperoxi-

C5b-9(m) complement complexes but both are incorporated into SC5b-9 complement complexes. SP-40,40 was initially identified in glomerular immune deposits and $S$ protein has been shown to be a component of the C $5 \mathrm{~b}-9$ in the glomerulus $(12,13)$. The two proteins are, however, not the same. S protein is a single-chain structure which may liberate a $15-\mathrm{kD}$ fragment $(11,33)$ whereas SP-40,40 is unequivocally a disulfide-linked heterodimer. Antibodies reactive with $S$ protein demonstrate no reactivity with SP-40,40 by ELISA and definitive proof of their separate identities is provided by the sequence analysis. The complete sequence of $\mathrm{S}$ protein is known (34) and distinct from the available sequence of SP-40,40.

SP-40,40 has probably not been previously detected in SC5b-9 preparations because it migrates with $S$ protein on unreduced SDS-PAGE gels. In a previous study, however, Bhakdi and Tranum-Jensen (35) demonstrated, as we have, the appearance of a $40-\mathrm{kD}$ band in SC5b-9 after reduction. Subsequently they reelectrophoresed, under reducing conditions, excised bands from a nonreduced SDS-PAGE gel of SC5b-9. Upon reduction, the excised "S-protein band" appeared to yield the characteristic 80 - and $65-\mathrm{kD}$ bands of $\mathrm{S}$ protein (35) and, in addition, a major $42-\mathrm{kD}$ subunit. With two-dimensional SDS-PAGE (nonreducing followed by reducing conditions), they confirmed the apparent reduction of

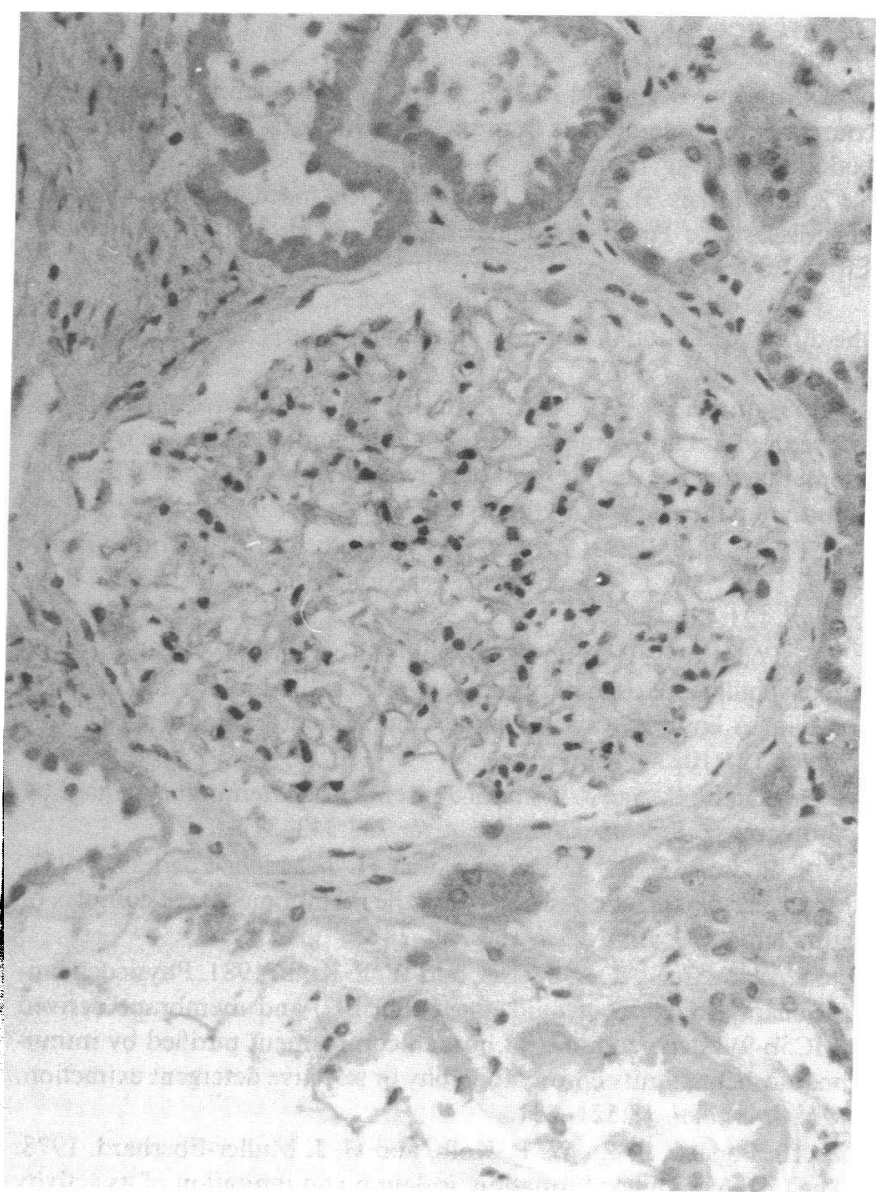

dase. Labeling of the thickened abnormal glomerular basement membrane is seen in the left panel (arrows). Glomerular labeling is not present in the normal kidney (right).

$\mathrm{S}$ protein to this major $42-\mathrm{kD}$ subunit. When subsequent studies with purified S-protein demonstrated its single-chain structure (11) or the liberation of only a $15-\mathrm{kD}$ fragment on reduction (33), the previous results were attributed to "secondary nicking of the S protein during the SC5b-9 isolation" (33). Degradation of $S$ protein in this manner has not been reported elsewhere and it appears far more likely to us that the excised "S-protein band" contained both S protein and SP-40,40, comigrating in the unreduced gels.

The role of SP-40,40 is unknown. Its incorporation into serum-derived SC5b-9 and its association with this complex in tissue immune deposits suggest, however, that SP-40,40 is an additional component of the SC 5b-9 complement complex.

Note Added in Proof. Subsequent investigations have revealed that residue 22 in the sequence of the $\alpha$ chain of SP-40,40 is E (Glu) and not $\mathrm{S}$ (Ser) as shown in Fig. 4.

\section{Acknowledgments}

The authors would like to thank Ms. G. Paterson and Mr. B. Classen for their help with some of the experiments.

Dr. Murphy was a recipient of a National Health and Medical Research Council Postgraduate Medical Research Scholarship during the period of this work. 


\section{References}

1. Murphy, B. F., and A. J. F. d'Apice. 1988. Identification of the components of glomerular immune deposits using monoclonal antibodies. Pathology. In press.

2. McCluskey, R. T. 1983. Immunological mechanisms in glomerular disease. In Pathology of the Kidney. R. H. Heptinstall, editor. Little, Brown \& Co., Inc., Boston. 301-386.

3. Couser, W. G., P. J. Baker, and S. Adler. 1985. Complement and the direct mediation of immune glomerular injury: a new perspective. Kidney Int. 28:879-890.

4. Hammer, C. H., M. L. Shin, A. S. Abramovitz, and M. M. Mayer. 1977. On the mechanism of cell membrane damage by complement: evidence on insertion of polypeptide chains from C8 and C9 into the lipid bilayer of erythrocytes. J. Immunol. 119:1-8.

5. Podack, E. R., G. Biesecker, W. P. Kolb, and H. J. Muller-Eberhard. 1978. The C5b-6 complex: reaction with C7, C8, C9. J. Im munol. 121:484-490.

6. Podack, E. R., and H. J. Muller-Eberhard. 1978. Binding of desoxycholate, phosphatidylcholine vesicles, lipoprotein and of the $S$ protein to complexes of terminal complement components. J. Immunol. 121:1025-1030.

7. Bhakdi, S., and J. Tranum-Jensen. 1983. Membrane damage by complement. Biochim. Biophys. Acta. 737:343-372.

8. Podack, E. R., J. Tschoop, and H. J. Muller-Eberhard. 1982. Molecular organization of $\mathrm{C} 9$ within the membrane attack complex of complement. J. Exp. Med. 156:268-282.

9. Ware, C. F., R. A. Wetsel, and W. P. Kolb. 1981. Physicochemical characterization of fluid phase (SC5b-9) and membrane derived (MC5b-9) attack complex of human complement purified by immunoabsorbent affinity chromatography or selective detergent extraction. Mol. Immunol. 18:521-531.

10. Podack, E. R., W. P. Kolb, and H. J. Muller-Eberhard. 1978. The C5b-6 complex: formation, isolation and inhibition of its activity by lipoprotein and the S-protein of human serum. J. Immunol. 120:1841-1848.

11. Dahlback, B., and E. R. Podack. 1985. Characterization of human $\mathrm{S}$ protein, an inhibitor of the membrane attack complex of complement: demonstration of a free reactive thiol group. Biochemistry. 24:2368-2374.

12. Rauterberg, E. W., H. M. Lieberknecht, A-M. Wingen, and E. Ritz. 1987. Complement membrane attack (MAC) in idiopathic IgAglomerulonephritis. Kidney Int. 31:820-829.

13. Falk, R. J., E. Podack, A. Dalmasso, and J. C. Jennette. 1987. Localization of $\mathrm{S}$ protein and its relationship to the membrane attack complex of complement in renal tissue. Am. J. Pathol. 127:182-190.

14. Westberg, N. G., and A. F. Michael. 1970. Human glomerular basement membrane: preparation and composition. Biochemistry. 9:3837-3846.

15. Oi, V. T., and L. A. Herzenberg. 1980. Immunoglobulin producing hybrid cell lines. In Selected methods in cellular immunology. B. B. Mishell and S. M. Shiigi, editors. W. H. Freeman \& Co., San Francisco. 351-372.

16. Hancock, W. W., N. Kraft, F. Clark, and R. C. Atkins. 1984. Production of monoclonal antibodies to fibronectin, type IV collagen and other antigens of the human glomerulus. Pathology. 16:197-206.

17. Falk, R. J., A. P. Dalmasso, Y. Kim, C. H. Tsai, J. I. Schein- mann, H. Gewurz, and A. F. Michael. 1983. Neoantigen of the polymerized ninth component of complement: characterization of a monoclonal antibody and immunohistochemical localization in renal disease. J. Clin. Invest. 72:560-573.

18. Lachman, P. J., M. J. Hobart, and A. P. Aston. 1973. Complement Technology. In Handbook of Experimental Immunology. D. M. Weir, editor. Blackwell Scientific Publications, Ltd., Oxford. 5.1-5.17.

19. Mason, D. W., and A. F. Williams. 1980. Kinetics of antibody binding to membrane antigens in solution and at the cell surface. Biochemistry. J.187:1-20.

20. Bhakdi, S., and M. Roth. 1981. Fluid-phase SC5b-8 complex of human complement: generation and isolation from serum. J. Immunol. 127:576-580.

21. Laemmli, U. K. 1970. Cleavage of structural proteins during the assembly of the head of bacteriophage T4. Nature (Lond.). 227:680-685.

22. Glossman, H., and D. M. Neville. 1971. Glycoproteins of cell surfaces: a comparitive study of three different cell surfaces of the rat. J. Biol. Chem. 246:6339-6346.

23. Burnette, W. N. 1981. "Western Blotting": electrophoretic transfer of proteins from sodium dodecyl sulfate-polyacrylamide gels to unmodified nitrocellulose and radiographic detection with antibody and radioiodinated protein A. Anal. Biochem. 112:195-203.

24. Cole, W. G., D. Chan, D. W. Chambers, I. D. Walker, and J.-F. Bateman. 1986. Deletion of 24 amino acids from the proalpha 1(1) chain of type 1 procollagen in a patient with the Ehlers Danlos syndrome type VII. J. Biol. Chem. 261:5496-5503.

25. Lems-Van Kan, P., H. W. Verspaget, and A. S. Pena. 1983. ELISA assay for quantitative measurement of human immunoglobulins IgA, IgG, and IgM in nanograms. J. Immunol. Methods. 57:51-57.

26. Scopes, R. K. 1974. Measurement of protein by spectrophotometry at $205 \mathrm{~nm}$. Anal. Biochem. 59:277-282.

27. Marchalonis, J. J. 1969. An enzymic method for the trace iodination of proteins. Biochem. J. 113:299-305.

28. Hancock, W. W., G. J. Becker, and R. C. Atkins. 1982. A comparison of fixatives and immunohistological techniques for use with monoclonal antibodies to cell surface antigens. Am. J. Clin. Pathol. 78:825-831.

29. Mathews, T. H., D. C. Mathews, J. Hobbs, and P. S. KincaidSmith. 1975. Glomerular lesions after renal transplantation. Am. J. Med. 59:177-189.

30. Goding, J. W. 1986. Analysis of antigens. In Monoclonal Antibodies: Principles and Practice. Academic Press, Ltd., London. 175.

31. Lentner, C., editor. 1984. Geigy Scientific Tables. Vol. 3. CibaGeigy, Basel. 135-161.

32. Putnam, F. W., editor. 1975. The Plasma Proteins. Structure, Function and Genetic Control. Vols. 1 and 2. Academic Press, Inc., New York. 481 pp., 436 pp.

33. Jenne, D., F. Hugo, and S. Bhakdi. 1985. Monoclonal antibodies to human plasma protein $\mathrm{X}$ alias complement $\mathrm{S}$ protein. Biosci. Rep. 5:343-352.

34. Jenne, D., and K. K. Stanley. 1985. Molecular cloning of Sprotein, a link between complement, coagulation and cell substrate adhesion. EMBO. (Eur. Mol. Biol. Organ.) J. 4:3153-3157.

35. Bhakdi, S., and J. Tranum-Jensen. 1982. Hydrophilic-amphiphilic transformation of the terminal SC5b-8 complement complex through tryptic modification: biochemical and ultrastructural studies. Mol. Immunol. 19:1167-1177. 